\title{
Improving uncertainty in Widmark equation calculations: alcohol volume, strength and density
}

Peter D Maskell, R. Alex Speers, Dawn L Maskell

This is the accepted manuscript (C) 2017, Elsevier Licensed under the Creative Commons AttributionNonCommercial-NoDerivatives 4.0 International: http://creativecommons.org/licenses/by-nc-nd/4.0/

\section{(cc) EY-NC-NO}

The published article is available from doi:

10.1016/j.scijus.2017.05.006 
2 Improving Uncertainty in Widmark equation calculations: Alcohol volume, Strength and Density

4

$5 \quad$ Peter D Maskell ${ }^{1 *}$, R. Alex Speers², Dawn L Maskell ${ }^{3}$

6

7 15chool of Science, Engineering and Technology, Abertay University. Dundee. 8 Scotland. UK.

$9 \quad{ }^{2}$ Canadian Institute of Fermentation Technology, Dalhousie University. Halifax. Nova 10 Scotia. Canada.

11 International Centre for Brewing and Distilling, Heriot-Watt University. Riccarton. 12 Edinburgh. UK.

${ }^{*}$ Author to whom correspondence should be addressed. 


\section{Abstract}

4 The Widmark equation is probably the most commonly used calculation for 5 medicolegal purposes. Recently the National Research Council (USA) and the 6 Forensic Science Regulator (UK) have called for the uncertainty of all results to be 7 given with all forensic measurements and calculations. To improve the uncertainty of 8 measurement of results from Widmark calculations we have concentrated on the 9 uncertainties of measurement involved in the calculation of alcohol, that of the volume 10 of alcohol, the concentration of alcohol and the density of alcohol as previous studies 11 have investigated some of the other factors involved. Using experimental studies, the 12 scientific literature and legal statutes, we have determined revised and improved 13 uncertainties of the concentration of ethanol for Widmark calculations for both the USA 14 and UK. Based on the calculations that we have performed we recommend the use of 15 Monte Carlo Simulation for the determination of uncertainty of measurement for 16 Widmark Calculations.

\section{Keywords}

19 Widmark, Alcohol Technical Defence, Back Calculation, Uncertainty of Measurement 


\section{Introduction}

Calculations using the Widmark equation [1] for medicolegal purposes, such as determining the blood alcohol concentration of a defendant at the time of an incident from a blood sample taken after the incident, are probably the most common calculations performed in forensic toxicology. As with all measurements and estimates that arise both in and from calculations there is a level of "uncertainty". Knowing the uncertainty of measurement allows us to have a level of certainty around a result and thus a better estimate of the true result [2]. The uncertainty of measurement is becoming increasingly important in forensic science allowing juries and non-experts to understand how accurate (and thus reliable) the results of the calculations and analysis are that they are being asked to evaluate. This is particularly important in cases where there are statutory limits (such as blood alcohol concentration) above which an offence has been committed [3]. Previously it has not been common practice to have uncertainty of measurement quoted with forensic analytical and calculated results within forensic reports and witness statements. However, in the past few years it is now becoming a requirement. As stated in the National Research Council (NAS) report on strengthening forensic science in the USA "All results for every forensic science method should indicate the uncertainty in the measurements that are made, and studies must be conducted that enable the estimation" [4]. In the UK the forensic science regulator expects "... all staff who provide factual evidence based on scientific methodology are additionally able to demonstrate, if required...the impact that the uncertainty of measurement associated with the application of a given method could have on any conclusion" [5]. With regard to the forensic calculations using the Widmark equation, Gulberg states "the only forensically appropriate way to present and interpret Widmark estimates is to include an assessment of their uncertainty" [6].

Prof. Eric Widmark initially studied the pharmacokinetics of alcohol consumption and the equation that he derived now carries his name. When using metric units the most common form of the Widmark equation (as described by Searle [7]) is:-

$C t=\frac{100 v z d F}{r M}-\beta t$

The mass of alcohol taken into the body can be separated out and expressed as: -

$A=v z d F$

Which then gives a revised Widmark equation (if the mass of alcohol consumed is calculated separately) of: -

$C t=\frac{100 A}{r M}-\beta t$

$\mathrm{Ct}=$ blood alcohol (ethanol) concentration at time $\mathrm{t}(\mathrm{mg} / 100 \mathrm{ml})$

$A=$ mass of alcohol (ethanol) consumed $(g)$

$\mathrm{M}=$ mass of the subject $(\mathrm{Kg})$ 
$1 \quad r=$ Widmark factor $(\mathrm{L} / \mathrm{Kg})$

$2 \beta=$ alcohol elimination rate $(\mathrm{mg} / 100 \mathrm{ml} / \mathrm{h})$

$3 \quad t=$ time since the drinking began $(h)$

$4 \quad \mathrm{v}=$ volume of the drink $(\mathrm{ml})$

$5 \quad \mathrm{~F}=$ bioavailability of the alcohol (ethanol)

$6 \mathrm{~d}=$ density of alcohol ethanol at $20^{\circ} \mathrm{C}$ (a constant)

$7 \quad \mathrm{z}=$ the strength of the drink Alcohol by Volume (ABV) \%v/v divided by 100.

In order to determine the uncertainty of any results calculated it is important to have the best estimations possible of the uncertainty of the various terms in the Widmark equation. Three relatively recent publications have both investigated and discussed the uncertainty around alcohol calculations [6-8] and offered suggestions for methods of calculation and the uncertainty that is inherent in those calculations. It is important to have reliable sources for the given uncertainty for each term in an equation. Unlike Zuba and Piekoszewski [8], Gullberg [6] gives some referenced estimates for the uncertainty (standard deviation (SD)) of various of the factors of the Widmark equation such as mass of the subject $(\mathrm{M})$, alcohol elimination rate $(\beta)$, the Widmark factor $(r)$ and the concentration of blood alcohol at time $\mathrm{t}(\mathrm{Ct})$. However, none of the publications give referenced error (standard deviation (SD) or coefficient of variance $(C V)$ ) for the calculation of the mass of ethanol consumed $(A)$. There is also no referenced information for the variables that make up the calculation of $A$, that of volume of ethanol consumed $(v)$, the ABV of the alcoholic beverage $(z)$ and finally the fraction of alcohol that is absorbed from the stomach $(F)$. As mentioned by all of the authors of the recent papers [6-8] determining the uncertainty of alcohol calculations improves the calculated estimates and further knowledge of the uncertainty of measurement of the individual variables would allow increased reliability of the results of any calculation using the Widmark equation.

The aim of this study is to determine, from the literature, published information and experimental data, improved estimates of the SD of measurements of alcohol density $(d)$, alcohol strength ( $\mathrm{z}$ ) and alcohol volume ( $v$ ). As the number of drinks (and overall volume of alcohol consumed in a "session") have been shown to have one of the largest contributions to the uncertainty of measurement $(\sim 13-21 \%$ depending on the calculation being performed [6-8]), we will also discuss an individual's "memory" of how much they have had to drink compared to their actual consumption. Due to the differing laws in the United States of America (USA) and United Kingdom (UK) we will discuss these regions separately where necessary. 


\section{Density of Ethanol (d)}

The density of ethanol $\left(\right.$ at $20^{\circ} \mathrm{C}$ ) is commonly quoted at $0.789 \mathrm{~g} / \mathrm{cm}^{3}$ in the forensic literature [9] and $0.78945 \mathrm{~g} / \mathrm{cm}^{3}$ in chemistry literature [10, 11]. They do not nevertheless give an estimation of uncertainty. Numerous publications have analytically measured the density of ethanol at $20{ }^{\circ} \mathrm{C}$ [11-18]. From these we calculated that the mean density ( \pm Standard deviation (SD)) of ethanol is $0.78974 \pm$ $0.00059 \mathrm{~g} / \mathrm{cm}^{3}$ (\% coefficient of variance $(\mathrm{CV})=0.07481$ ). Thus, it would be more accurate to use these values both in calculations using the Widmark factor and for calculation of uncertainty when using the Widmark equation.

\section{Variation on the Strength of Alcohol (z)}

\subsection{Labelling Requirements of ABV for alcoholic beverages}

The strength of alcohol (ethanol) is commonly measured as the percentage of alcohol by volume $(\% \mathrm{v} / \mathrm{v}$ or $\mathrm{ABV})$ and is defined as the number of millilitres of pure ethanol present in 100 millilitres of solution at $20^{\circ} \mathrm{C}$. In the UK and $\mathrm{EU}$ it is a legal requirement to give the $A B V$ on the label of any packaged alcoholic beverage, and also to advertise the ABV of alcoholic beverages, such as those sold in a pub or bar [19]. In the USA there is no legal requirement for the labelling of alcoholic beverages with the ABV for either packages alcoholic beverages or off-sales [20]. Some packaged beverages in the USA are labelled (around 17\% based on the most up-to-date study from 1999 [21]). The allowable error of ABV in the USA and EU are presented in Table 1.

\subsection{Variation in the labelled $A B V$ and actual $A B V$}

Although there are legally allowable variations from the labelled $A B V$, it is possible that the actual $A B V$ in alcoholic beverage may be more accurate than the allowable legal variations of $A B V$. To determine if the published $A B V$ measurements are likely to be more accurate than required by law we investigated the methodology to determine $A B V$ from a set of brewing data. The most common method of determining the alcohol content of alcoholic beverages in breweries is that of measurement of the attenuation in the specific gravity by measuring the gravity at the start of fermentation (original gravity (OG)) and then after fermentation has been completed (final gravity (FG)) [22]. Apparent specific gravity is defined as "the density of a sample at $20^{\circ} \mathrm{C}$ divided by the apparent density of an equal amount of water at $20^{\circ} \mathrm{C}$ ". Water has an apparent specific gravity of 1.0000 at $20^{\circ} \mathrm{C}$. [23]. Specific gravity measurements are not the only methods of determination of alcohol content further methods are given in [24].

For measurements of specific gravity, a number of empirical equations are available depending on the mathematic prowess of the brewer. 
1 The simplest is [25]:

$2 \quad A B V=(O G-F G) * 131.25$

$3 \quad \mathrm{ABV}=$ alcohol by volume $(\% \mathrm{v} / \mathrm{v})$

$4 \quad \mathrm{OG}=$ original gravity (before fermentation has commenced)

$5 \quad F G=$ final gravity (after fermentation has finished)

6 In the UK, the original and final gravities are multiplied by 1000 and a mandated 7 specific factor (f) $(0.125-0.135)$ replaces the 131.25 when calculating the ABV this 8 factor is dependent on the value of $O G-F G$ and is used for the purpose of calculating 9 the ABV for the determination of the excise duty (Excise notice 226: beer duty):-

$10 \quad A B V=(O G-F G) * f$

11 In the USA a beer table allows the calculation of ABV using a hydrometer for excise purposes (Code of Federal Regulations (Title 27 of the CFR PART 30))

Another relation based on the Balling equation [26] but expressed in terms of specific gravity rather than ${ }^{\circ}$ Plato (roughly equivalent to \% sugar) [27] can be used:

$15 \quad A B V=\frac{76.08(O G-F G)}{1.775-O G} \times\left(\frac{F G}{0.794}\right)$

Aside from the use of specific gravity values to measure the starting wort (a carbohydrate rich liquid which is fermented into beer) and final beer densities much of the industry uses the 'Plato scale. A fluid of 'density' of $1.0{ }^{\circ} \mathrm{P}$ is roughly equivalent to a sugar solution of 1.0 on a \%w/w basis. Aside from equations 4,5 and 6 , a more exact empirical equation based on the difference between the starting and final densities expressed in ${ }^{\circ}$ Plato was recently updated and the accuracy much improved by Cutaia et al. [28]

$A B V=\left(0.38726 x(O E-A E)+0.00307 x(O E-A E)^{2}\right) x\left(\frac{F G}{0.794}\right)$

$\mathrm{OE}=$ original extract in ${ }^{\circ}$ Plato (before fermentation has commenced)

$\mathrm{AE}=$ apparent extract in ${ }^{\circ}$ Plato (after fermentation has finished)

An expression to convert extract values (i.e., $O E$ or $A E$ ) to specific gravities (OG or FG respectively) has also been reported by Cutaia et al. (eq. 10), [34]. 
1 In order to determine the accuracy of equations 4,5 and 6 in determining ABV we used industrial data sets from fermentations where measurements of $O E, A E$ and alcohol (\% w/w) were converted to $\mathrm{OG}, \mathrm{FG}$ and $\mathrm{ABV}$ by equations 10 and 14 from the paper by Cutaia et al. [34]. An estimate of ABV was also determined using OE and $A E$ values and equation 7 reported above. These values were the same fermentation data sets as detailed in [28] and further information on them and their origin can be found therein. The predicted ABV was regressed on the true ABV using Systat Ver 11 (Systat Software Inc., San Jose, $C A$ ) and forcing the estimate of ABV through the origin. The coefficient of determination and the standard error were calculated. The results (not shown) showed a clear linear relationship between the predicted \%v/v calculated and the actual alcohol content using equations 4-7 ( $\left.r^{2} 0.99\right)$. As expected, the use of equation 7 from Cutaia et al. [28] gave the least amount of error $( \pm 0.130$ $\% \mathrm{ABV}$ ) when predicting the actual \%ABV from gravity data. Equation (5) gave a similar amount of error $( \pm 0.131 \% \mathrm{ABV})$, the largest error was observed with equation (4) that of $( \pm 0.141 \% \mathrm{ABV})$. Although these errors for determination of $\mathrm{ABV}$ are well within the error allowed by HMRC in the UK, it would be advisable to use the largest error in ABV in the calculation of uncertainties. In large breweries (such as the top global breweries) that use high gravity brewing [29] where the beer is brewed at a higher ABV than it will be sold at, then diluted to the required $A B V$ using water, there is likely to be a greater accuracy in the final ABV. Due to the use of IR-ATD with a measurement accuracy of $\pm 0.01 \% \mathrm{ABV}$.

\subsection{ABV variation in alcoholic beverages in the USA}

In the USA it is not a federal requirement to label with the ABV, it is also not a legal requirement to give the $A B V$ of alcohol when served in bars. When there is no specific information on the brand of alcoholic beverage consumed, there are limited sources of information. It is possible to make some general assumptions based on the alcohol beverage consumed. In the USA in 2002, the last year for published compiled data, wine had an average strength of $11.45 \%$ [30, 31], spirits 37\% [30] and beer in 2005 had an average ABV of $4.5 \%$. [32] Unfortunately no error was given with these results. These results were also compiled from industry data rather than direct measurement. The last year where data is available for beer ABV from direct measurement is 1997 where beers for sale in Washington state were analysed [21]. The study investigated ales $(n=256)$, lagers $(n=113)$ and various sub-groups of these categories. Ales had a mean \pm SD ABV of $5.51 \pm 1.23 \%$ (Median $5.25 \%$; Range $2.29 \%-12.69 \%$ ). Lagers had a mean ABV of $5.32 \pm 1.43 \%$ (Median $5.00 \%$; Range $4.02 \%-15.66 \%$ ). The study gives more detail on the subgroups of the ale and lager classes for those that are interested and require more accurate calculations of uncertainty. It is to be noted that the average ABV of beers across the USA has decreased in recent years from $4.72 \%$ in 1997 to $4.5 \%$ in 2005 [32], suggesting that a new study investigating the average ABV of beer (with standard deviation) would be beneficial in the estimation of uncertainty for forensic calculations. 


\subsubsection{Deviations from the labelled ABV}

Even when beverages are labelled with $A B V$ there will be deviations in the labelled and actual ABV. In the study by Logan and colleagues for beverages labelled with $A B V$ the average difference between the labelled ABV and the actual ABV was 0.03 $\pm 0.40 \%$ (mean \pm SD) less than labelled (range $0.98 \%$ below $-1.62 \%$ above) [21] For wine a systematic study was carried out on the ABV on wine labels data from over 100,000 wines entering Canada between 1992 and 2009 [33]. This study found that there was an underreporting of the label ABV on average (mean) by $0.13 \% \mathrm{ABV}$. For the wines that were underreported the average (mean) underreporting was $0.42 \%$ ABV (57.1\% of total number sampled). $32.2 \%$ of the wines samples over reported the $A B V$ of an average (mean) of $0.32 \%$ ABV [33]. Further information into the variation of labelled $A B V$ and actual $A B V$ in the USA can be found from the annual Alcohol Beverage Sampling Program (ABSP) (https://www.ttb.gov/sampling/) carried out by the USA Alcohol and Tobacco Tax and Trade Bureau (TTB) in order to determine if the labelling is likely to mislead customers. The TTB randomly sample alcoholic beverage to check compliance. Table 2 gives an up-to-date summary on the TTB compliance program and suggest that currently there may be less variation in ABV than suggested by the Logan study [21]. There is a greater level of certainty in the UK with $A B V$ due to the labelling regulations than in the USA.

\subsection{ABV variation in alcoholic beverages in the UK}

In the UK all alcoholic beverage for sale must be labelled with the ABV. If the type and brand of drink can be remembered by the individual then it can be reasonably simple to determine $A B V$ for calculation. If the exact beverage type is not available there are various sources that can be used for a reasonable estimate. Table 3 gives data of the ABV ( \pm standard deviation) of various common alcohol types from Tesco.com the largest supermarket in the UK [34] and from LWC drinks the UKs largest Independent drinks wholesaler [35]. For the craft type beer there are two sources of data. The Society of Independent Breweries (SIBA, www.siba.co.uk) publish the results of a survey of members each year. This survey usually has data from $\sim 35 \%$ of the membership ( $\sim 350$ breweries) and publishes the average ABV of the beers brewed by members. In 2015 the average ABV (mean \pm SD) was $4.17 \% \pm 0.521 \%(n=266)$ [36] this was similar in 2016 where the average ABV again was (mean \pm SD) $4.17 \% \pm$ $0.44 \%(n=295)$ [37]. Further information on the variation of ABV for various types of UK beer can be estimated from data obtained from the Great British beer festival, an annual beer festival in the UK with over 300 different beers. Table 4 shows the average (mean, mode), Standard deviation and \%CV of the various beer types (as defined by CAMRA) of golden ale, bitter, indian pale ale (IPA), mild, porter, stout and "speciality" [38] from the 2016 Beer festival. Overall the mean ABV of all the beers at the festival 
$1 \quad(n=386)$ was $4.4 \pm 0.7 \%$ (Range $3.0-7.5 \%)$. From these data it was possible to 2 calculate the mean ABV ( \pm SD) of beer $(4.5 \pm 0.8 \%, n=552)$; wine $(12.4 \pm 1.5, n=$ $3399)$ and spirits $(39.3 \pm 4.1, n=147)$ in the UK. This information can be used when only limited information about the beverage type is known.

\section{Variations in the volume(s) of Alcoholic Beverage (v)}

\subsection{UK and USA Drinks Measures for on-sale purchases.}

As with concentration of alcohol content in alcoholic beverages there is also an uncertainty of measurement with the labelled or dispensed volume of alcoholic beverages. Alcoholic beverages are sold in three forms where volume is important. Pre-packaged (for example buying a bottle of an alcoholic beverage), a serving measure (for example buying a dispensed beer at a bar) and a transfer measure (for example a "shot" measure when making cocktails). Table 5 outlines the variations in volume that are allowed under US and EU regulations. In the EU legislation covers all of the forms of alcoholic beverage that are sold (European Commission Directive (87/250/EEC) article $3 \mathrm{ABV})$. However, in the US the only specific weights and measures legislation cover pre-packaged drinks. There is no direct legislation covering serving measures apart from those that protect against deceptive trade, so commonly in the USA when purchasing a beverage at a bar neither the volume nor ABV will be known [20].

In the UK the standard dispensed unit for beer is a pint $(\sim 568 \mathrm{ml})$, whereas in the US the standard pint is 16 fluid oz $(\sim 473 \mathrm{ml})$ and pint glasses are not required to be legally stamped to confirm the volume. This has led to reports of restaurants replacing $16 \mathrm{fl}$ oz glasses with $14 \mathrm{fl} \mathrm{oz} \mathrm{glasses} \mathrm{with} \mathrm{similar} \mathrm{profiles} \mathrm{and} \mathrm{also} \mathrm{of} \mathrm{overly} \mathrm{large} \mathrm{"heads"}$ of foam on beers leading to pints of significantly less volume than $16 \mathrm{fl} \mathrm{oz}$. Studies in the USA have shown that the average size of a glass of wine $( \pm 95 \% \mathrm{Cl})$ was $6.18 \mathrm{fl} \mathrm{oz}$ $(5.95,6.41), \mathrm{n}=131$; the average glass of beer was $14.10 \mathrm{fl}$ oz $(13.50,14.70), \mathrm{n}=56$; the average glass of spirits was $5.28 \mathrm{fl} \mathrm{oz}(5.06,5.50), \mathrm{n}=288$. Further sub divisions (such as red wine, white wine etc.) of the various beverages are given in the paper [20]. Further study in this area would be beneficial.

In the UK even though there is a legal requirement to provide a full pint (Weights and Measures Act 1985) a 1982 court ruling (Bennett v Markham [1982] 3 AllER 641) allows a "reasonable" head of foam. Industry regulations allow a $5 \%$ head of foam on a beer, although a full pint should be provided if asked [39]. Studies have shown the mean volume of liquid was $96.06 \%$ of a pint. (3.94\% short) $(n=88)$ however in one pub it was found to be $11.8 \%$ short [40]. In the UK it is possible to purchase pint glasses that are either a pint to the brim or to the line. The line measured glasses allow a head to be included without the dispensing of less than a full pint. Pubs and bars in the UK can choose which pint glasses they use; unfortunately there is no data available on the commonality of each glass type in the UK. 


\subsection{Variations in fill volumes of packaged alcoholic beverages}

In the EU pre-packaged alcoholic beverages must not on average be below the nominated volume in a single batch. There is a set tolerable negative error (TNE) (see table 5) that is either a set volume or percentage of volume and packers must set limits on the number in a batch that can be short by the TNE (Weights and Measures (Packaged Goods) Regulations 2006). No package should be short by twice the TNE. In the USA, as can be seen in table 5 the allowable fill variation depends on the size of the bottle and varies between 1.5 to $4.5 \%$ of the labelled volume (27 CFR 19.356). Confirmation on fill volume around the world is either measured by fill height, weight or dispensed amount [41]. There is limited information on the actual variation in packaged fill volume. A survey of industry suggested on average an overfill on packaging lines between 0.5 and $4 \%$ [42], suggesting that beverages are unlikely to be under-filled in the UK even though the packaging technology should theoretically allow variations of less than $1 \mathrm{ml}$ [43]. A study in 2012 investigated fill volume variation and gives the best example of real fill data from a large brewery producing 1.9 million litres per day. The target fill was $750 \mathrm{ml}$, based on the values provided the average fill was found to be $752 \mathrm{ml} \pm 8.13 \mathrm{ml}$ (range $705 \mathrm{ml}-775 \mathrm{ml}$ ) [44]. The average and the standard deviation are within both the required EU and USA regulations (EU $735 \mathrm{ml}$ $765 \mathrm{ml}$; US $762 \mathrm{ml}-745 \mathrm{ml}$ ), however the ranges are not within the legal limits. Automated bottling plants, like the one outlined in [44], are likely to have a greater reliability than those in smaller breweries/distilleries that use may use manual methods of filling. The TTB study (table 2) shows that in the USA there have been no recorded incidences of deviation from the filling legislation in the past 4 years that data is available.

\section{Number of drinks consumed}

Depending on the type of Widmark calculation being carried out it can be important to know the number of alcoholic beverages that have been consumed by the subject. This can be problematic in that the drinker may not a) remember how many "drinks" they have consumed b) they may lie about the amount of alcohol they have consumed and c) they may have been at home and not poured measures that alcoholic beverages are commonly sold in. In this section we review the studies that have been conducted in order to give a better understanding of the uncertainty that may be involved with the self-reported recall of the number of drinks consumed.

\subsection{Accuracy of self-reporting of alcohol consumption}

A limited number of studies have been performed in order to try to determine the accuracy of self-reporting of alcohol consumption (in terms of the number of "drinks" (as defined by the drinker)) vs. the actual number of drinks consumed. 
1 There have been a number of different approaches to this question. 1) Observation of the subject(s) either in a controlled environment or in "the wild" [45-47]; 2) Comparison of measured blood alcohol concentration (BAC) compared to estimated BAC based on reported self-drinking on emergency department admissions [48, 49] or 3) 5 Comparison of "real time" recording of consumption vs. retrospective self-reports [50]. 6 All of these types of reporting methods have pros and cons that are discussed further in the individual publications, however, some salient points that are of importance in alcohol calculations were obvious.

In all of the studies there was a difference in the alcohol consumed and the alcohol reportedly consumed. In the study where the subjects were observed consuming alcoholic "drinks" in a simulated social environment there were 58 males (age 25-54) that drank in groups of 4 . The subjects were able to drink ad libitum for $6 \mathrm{~h}$ then either 1 or 2 days later they were interviewed to see the number of alcoholic drinks they had consumed. The mean number of drinks actually drunk was 11.4 (range 7-16) with the number recalled being less at 10.5 (range $6-15.5$ ). When divided into "light" drinkers (7-11 drinks) the mean consumed was 9.76 drinks with an actual of consumption of 9.40 drinks. The heavy drinkers (12-16 drinks) actually consumed a mean of 13.37 drinks with the recalled amount being 11.72 drinks [46]. This trend of the "heavier" drinkers having less accurate recall of consumption is confirmed in a study in a more realistic drinking environment where data was collected by volunteers shadowing participants ( $n=62 ; 30$ male, 32 female; age $18-25)$ in normal social settings. The participants were again interviewed $1-2$ days after the drinking. These results show that participants tend to be accurate at remembering the number of drinks consumed when consuming up to 8 drinks. When looking in more detail at the data subjects overestimated when consuming up to 4 drinks (mean observed drinks 1.7, mean reported drinks $1.8, \mathrm{n}=31$ ) and this was repeated with up to $5-8$ drinks with a slight overestimation of drink consumption (mean observed drinks 5.8, mean reported drinks $6.0, n=50)$. When subjects drank more than 8 drinks $(9-12$ drinks) the participants underreported the number of drinks consumed (mean observed drinks 9.0, mean reported drinks $8.3, n=33$ ). When the subjects consumed $>12$ drinks they under estimated their consumption by around 2 drinks (mean observed drinks 14.8, mean reported drinks $12.8, n=15)$. [45] A further study where the 69 participants (18 - 36 years; $59 \%$ male) logged their drinking on a night out in real time using a phone app and were then asked to recall how much they had drunk $24 \mathrm{~h}$ later, again shows that participants underreport their drinking that increased with the number of drinks consumed. The participants logged an average (mean \pm SD) of $8.45 \pm 5.97$ drinks during the evening whilst only recalling consuming $4.17 \pm 3.02$ drinks a mean difference of 4.28 drinks less than actually consumed, a $49.3 \%$ difference [50]. When looking at longer term recall of alcoholic beverage consumption (average 27 days) a study again shows an underreporting of alcohol consumption. This study investigated 141 drivers who were recruited on arrival at a selection of bars in an $80 \mathrm{~km}$ radius of Vermont, New England USA. The drivers were not aware their drinking was being observed and recorded. They again showed that recall of the number of drinks 
1 consumed worsened with increasing number of drinks. Light to medium drinkers (1-

25 drinks) all tended to estimate $2-3$ drinks. They reported light drinkers $(1-2$ drinks)

3 tend to overestimate and medium to heavy drinkers ( $<4$ drinks) tend to overestimate

4 [47]. Unfortunately, the study gave no more detail on the drinking. The underestimation

5 in these studies could be due to a number of reasons; the well know effects of ethanol

6 consumption on memory [51], the phenomena of people tending to underestimate the number of items as their quantity increases [52], social stigma [49] and actually deliberately distorting the results due to possible legal consequences [49]. The final approach to self-reported drinking was investigating the correlation of estimated ABV (based on self-reported drinking) compared to measured ABV after admission to the emergency department (BAC). In the two studies $[48,49]$ they found that drivers under-reported more than non-drivers and men under-reported more than women. Intoxicated subjects (defined as above the quoted legal US limit of $100 \mathrm{mg} / 100 \mathrm{ml}$ ) $14 \%$ actually over reported, compared to none of the non-intoxicated patients (above $10 \mathrm{mg} / 100 \mathrm{ml}$ but below $100 \mathrm{mg} / 100 \mathrm{ml}$ ) only 7 patients ( 5 drivers and 2 passengers) from a sample of 181 denied alcohol consumption but tested positive $(>10 \mathrm{mg} / 100 \mathrm{ml})$ [49]. Although it is not possible to determine the drinks consumed this study illustrates again differences between declared drinking and actual alcohol consumed. The mean BAC difference between EBAC and BAC was $-75.71 \mathrm{mg} / 100 \mathrm{ml}$ (SD $115.82 \mathrm{mg} / 100$ $\mathrm{ml}) \mathrm{n}=107$ ) with drivers $-98.47 \mathrm{mg} / 100 \mathrm{ml}(\mathrm{SD} 106.19) \mathrm{n}=78$. Only $60 \%$ of patients would give information suitable for calculation of EBAC. Overall respondents would admit to drinking alcohol but would be "unable or unwilling to describe the exact quantity and frequency of alcohol consumption" [49]. In the second study [48] the mean difference in EBAC and BAC was $-79.27 \mathrm{mg} / 100 \mathrm{ml}$ (SD $108.27 \mathrm{mg} / 100 \mathrm{ml}$ ) $\mathrm{n}=128)$ with drivers $-113.18 \mathrm{mg} / 100 \mathrm{ml}($ SD 96.78) $\mathrm{n}=68$ [48] there was a similar refusal rate of $58 \%$ when compared to the other study (60\%) [49] and that of Perrine and colleagues [47]. These studies show that in short term recall (24 - 48hr) of drink consumption, drinkers of $>8$ drinks tend to underestimate the number of drinks they have consumed by around on average of $0.3-0.7$ drinks. There is a greater divergence between actual number of drinks consumed and reported amount of drinks consumed with $>8$ drinks where the drinkers reported a mean of around 1.65 -2.00 less drinks reported than actually consumed. This can go up to an underreporting of $\sim 4.8$ drinks when 15 drinks have been consumed. Below 8 drinks there is a tendency of a slight over estimation of the amount of alcohol consumed but only by around 0.1 - 0.2 drinks. The ability to recall the number of drinks, as expected due to memory, was reduced when longer time periods where involved ( 27 days). Other research has shown that men are more likely to underestimate than women and drivers are more likely, as expected due to the legal implications, more likely to underestimate the number of drinks consumed [48, 49]. Further studies that focus on the forensic variation in alcohol self-reporting, reporting of drink consumption of others by witnesses and also in a variety of cases would be useful to allow more accurate estimations in future work. 


\subsection{What is the size of a "drink" in a pub/bar?}

Evidence clearly shows an underreporting of consumption of the number of "drinks" reportedly consumed compared to actual consumption after both 1 - 2 days and 27 days in personal recall studies. In all of these studies they did not investigate the size of the "standard" drink or what people's perception of a "drink" is. The size of a standard drink varies between countries with a range of $8-20 \mathrm{~g}$ of pure ethanol in a "standard measure" [53]. In the UK drinks are measured in "UK Units" (8 g pure ethanol) with the "standard" drink in the USA being $14 \mathrm{~g}$ of pure ethanol [54]. It is important to understand what people consider to be a standard "drink" as in the UK 51 $\%$ of sales of alcoholic beverages are "off" sales [55], with around $76 \%$ of sales in the USA being off sales [56] . In the UK it is easier for people to recall the number of drinks they have consumed if they are purchasing from a bar or shop as these will come prepackaged or will be a set size (with some variation of course). In the USA for bars, due to there being no federal legislation controlling the size of a drink measure when in draught or poured, and at home in both the UK and USA, where consumers can define their own "drink" size it is important to have knowledge of these sizes in order to be as accurate as possible in Widmark calculations. The size of a drink in a USA bar is covered in section 4.1 .

\subsection{What is the size of a self-poured "standard" drink?}

In countries that serve set measures of alcoholic beverages in bars/pubs it is possible to give a good estimate of the volume of a beverage consumed assuming the drinker has a good memory for the number of drink they have consumed. The estimation of the size of a "standard" drink for off sales is however more complicated as people can have any volume of beverage that they choose without any legal restrictions on the size. Thus each drinker will have their own definition of the size of a "drink". The best way to determine the volume of drink that has been consumed would be to obtain the glass that has been used for drinking and ask for the volume (or level) to be indicated by the drinker. The volume of a "standard" drink is important for the determination of the average alcohol consumption of people around the world. This has led to studies looking at the average (mean) "standard" drink that people pour themselves. As can be seen in table 6 the "standard self-pour measure" of wine, beer and spirits either study the number of units or the volume of the drink poured. The size of an average drink has been shown to be affected by the drink (beer, wine, spirits) the glass that it is poured into and also the gender of the person pouring the drink. The data from Wilkinson and colleagues [57] and Kerr and colleagues [58] (Table 6B) illustrates that the number of units in a standard drink increases with the alcohol concentration, this will partially be because of the increased amount of alcohol per $\mathrm{ml}$ of the drinks. Based 
on the philosophy of being in the motorists favour the estimates of uncertainty that are most suitable are those of Kerr and colleagues [58]. As these results are in UK units they would need to be converted to $\mathrm{ml}$ for use in Widmark calculations. It is also important to note that studies have shown the glass type used has an effect on the size of drink that is poured, such that when asked to pour the same volume $(44.3 \mathrm{ml})$ of a beverage into a short-wide glass and a tall thin glass of equal volume the subjects poured significantly more $(54.6 \mathrm{ml}$ and $46.4 \mathrm{ml}$ respectively) into the tall think glass compared to the short-wide glass $(17.8 \%$ more) [59]. The size of the container also has an effect with larger amount of liquid being poured into larger containers with the larger the glass size the larger the discrepancy [60,61]. In a study into hand poured measures of spirits the subjects were asked to pour a "single" pub measure $(25 \mathrm{ml})$ and a "double" pub measure $(50 \mathrm{ml})$ into three types of glasses (straight sided half pint glass, whisky tumbler and wine glass). The mean for each glass for a single measure was $27.2 \pm 10.0 \mathrm{ml}, 30.1 \pm 10.3 \mathrm{ml}, 26.3 \pm 8.7 \mathrm{ml}$ respectively. For a double measure $51.3 \pm 17.7 \mathrm{ml}, 54.7 \pm 17.9 \mathrm{ml}, 46.7 \pm 14.7 \mathrm{ml}$. Showing that overall the greatest deviation from the expected volume was when pouring into "whisky type tumblers" [62].

\section{Estimated uncertainty of the amount of ethanol (A)}

It is possible to calculate the uncertainty of the amount of ethanol $(A)$ by either using the method of general error propagation (GEP) [63, 64] used by Searle [7] and Gullberg [6] in their calculations of uncertainty of Widmark calculations or that of the Monte Carlo simulation method [65-67] as used by Zuba and Piekoszewski [8].

\subsection{General Error Propagation}

Based on the data that has been discussed above it is possible to give estimations of the uncertainty of volume (v), alcoholic strength (z), density of alcohol (d) and the number of drinks (or volume of beverage) consumed. Using the standard deviations that are known for the values $v$ (volume), $z$ (concentration), $d$ (density) and common general error propagation (GEP) methodology it is possible to determine the standard deviation of the amount of pure alcohol consumed $(A)$ using equation 8 . It has been assumed that $F$ (bioavailability) $=1$ and is thus not included in the calculations.

$$
\frac{\Delta A}{A}=\sqrt{\frac{\Delta v}{v}+\frac{\Delta z}{z}+\frac{\Delta d}{d}}
$$

It can be simpler to use the coefficient of variance (the standard deviation of each variable divided by its mean) with $A$ being a function of 3 variables 
$A=f(v, z, d)$

This gives equation 9 .

$e_{A}=\sqrt{e_{v}^{2}+e_{z}^{2}+e_{d}^{2}}$

6

$e_{A}=$ coefficient of variance of amount of alcohol consumed

$e_{v}=$ coefficient of variance of volume of drink consumed

$e_{d}=$ coefficient of variance of the density of ethanol

$e_{z}=$ coefficient of variance of the alcoholic strength of the drink (ABV)

\subsection{Monte Carlo Simulation}

Monte Carlo simulations are a method that uses inferential statistics, where a random sample tends to exhibit the same properties as the population from which it is drawn, to estimate the value of an unknown quantity. Simply we use randomly generated numbers for all of the input parameters to the model (in this case the Widmark equation) where each of the input parameters (such as weight, elimination rate constant etc.) of the model have a predetermined probability distribution, such as a normal distribution, rectangular distribution and triangular distribution). The predetermined probability distributions can be based (as in this study) on experimental data. As expected the approximation of the unknown quantity becomes better with an increase in the number of iterations ( $n$ ) that are completed. [66]). Further detail on the theory and use of Monte Carlo simulations can be found in the following references $[66,68]$.

27

The uncertainty of amount of alcohol consumed $(A)$ when using the Monte Carlo method was calculated using GUM Workbench EDU Software Version 2.4.1.384 (Metrodata $\mathrm{GmbH}$, www.metrodata.de) using 2,000,000 iterations. The modelling assumed a rectangular distribution (as the data for each input parameter was equally likely to fall between the ranges given) for each input parameter. The standard deviation for the input parameter was entered as $1 \sigma(68 \%)$. For the legal range of ABV allowable (either $0.5 \%$ or $1.5 \%$, depending on the state concentration) was assumed to be at $3 \sigma(99.7 \%)$ and was divided by 3 to give $1 \sigma(68 \%)$ for use in the modelling.

In order to determine if the revised information in this study gave a reduced variation

\subsection{Revised estimation of the uncertainty of the alcohol content in beverages.}

in the calculated alcohol concertation quoted by Gullberg [6] and Zuba [8] we used the 
1 GEP method using equation 9 (detailed in section 6.1) and the Monte Carlo method using equation 2 (detailed in section 6.2) to calculate the coefficient of variance (CV) of alcohol. We utilised the values of the drinks given in the Gullberg study (Beer, $12 \mathrm{fl}$ oz (us), 4\% ABV [6]) and the Zuba study (Spirit, 250ml, 40\% ABV [8]) but using the country specific variation volume and ABV from this study (USA for Gullberg, UK for Zuba). For Gullberg the volume was converted from $\mathrm{fl}$ oz (USA) to $\mathrm{ml}$. It was assumed that the alcohol was bottled and the ABV was given on the label. For the Zuba data it is assumed that the drink was a single measure bottle. The value of uncertainty (SD) for ABV was obtained from Table 1 and volume from Table 5 . The values used to calculate the precision $(\% \mathrm{CV})$ of the ethanol result and the calculated results are given in table 7A and 7B. As expected due to the improved uncertainty estimates from this paper compared to the publications by Gullberg [6] and Zuba [8] the \%CV of the alcohol estimate was reduced. The Monte Carlo Method gave a lower calculated uncertainty (Table 7B) the GEP method (Table 7B) for both of the calculations of Beer (2.69 \%CV for GEP compared to $1.69 \% \mathrm{CV}$ for Monte Carlo) and Spirits (1.85\%CV for GEP compared to $1.29 \% \mathrm{CV}$ for Monte Carlo). These results suggest that the Monte Carlo Method of determination of the uncertainty, at least for calculation of the amount of alcohol, is the preferred method of calculation over the standard GEP methodology.

\subsection{Proportion of the contribution of the Improved Ethanol Volume, Strength and Density Estimates to Widmark Calculations}

In order to determine the proportional contribution of each of the seven variables to the total uncertainty in the Widmark equation $(v, z, d, r, W, \beta, t, f$, when calculating blood alcohol concentration); and the variables $C \max , \beta, t, r, W, d$ and $z$, when calculating the number of drinks consumed). We used the revised uncertainty determine in this study for $v, z$ and $d$ the remaining variables were based on the data provided by Gullberg [6].The relevant equation (equation 1 for blood alcohol concentration and equation 10 for number of drinks consumed) was entered in to GUM Workbench EDU (Version 2.4.1.384). As before we used type B errors that were assumed to exhibit a rectangular distribution. There were 2,000,000 iterations. The variables were all assumed uncorrelated except $r$ and $\beta$ where the correlation was -0.135 (based on the study by Gullberg and Jones [69]). As can be seen from the data in table $8 \mathrm{~A}$ there was a reduction in the total error contribution of the volume (v), the density (d) and the ABV ( $z$ ) to the overall calculation when the revised uncertainties were used, as expected. The total error contribution was $19.7 \%$ (based on the \%CV provided by Gullberg) compared to $8 \%$ (based on the \%CV from this study). The largest reduction in contribution to the total uncertainty observed was with the volume $(14.1 \%$ to $3.6 \%)$. This led to an overall reduction in the uncertainty of the calculation of Cmax of $0.5 \%$ (from $12.5 \%$ to $12 \%$ ) and a reduction of the SD of the mean Cmax calculated (114 $\mathrm{mg} / 100 \mathrm{ml}$ ) of $1 \mathrm{mg} / 100 \mathrm{ml}$ (from $14.5 \mathrm{mg} / 100 \mathrm{ml}$ to $13.5 \mathrm{mg} / 100 \mathrm{ml}$ ). This of course is 
1 only a reduction in the precision of the result it does not look at the accuracy of the

2 result.

3 It is also possible to look at the influence the improvement in the uncertainty has on

4 the use of the Widmark equation has for the calculation of the volume of ethanol that

5 has been consumed when the BAC is known. Again the data has been taken from

6 Gulberg [6] the transformed equation is:-

$7 \quad v=(C t+\beta t) \frac{r M}{100 z d}$

The variables used in the determination of the proportional uncertainty for density (d) and $\mathrm{ABV}(\mathrm{z})$ are detailed in table $8 \mathrm{~B}$. There is a slight reduction in the overall proportional uncertainty of $1.9 \%(6.4 \%$ to $4.5 \%)$ with no change in the calculated SD of $\pm 255 \mathrm{ml}$ or the overall \%CV of $14 \%$. This is to be expected as they are only two variables compared to three variables above. The volume was the variable of the three with the largest contribution to the total uncertainty.

\section{Conclusions}

The results in this study allow forensic practitioners to both calculate and use reference variables in order to improve their calculations of uncertainty when using the Widmark equation. Although they are small improvements in uncertainty further improvement of the reliability of Widmark calculations could be obtained with further work to determine variance of the other parameters in the Widmark equation.

\section{Acknowledgements}

The authors wish to thank Sadie Boniface for her help with the research areas of self-reported drinking and drink measures and to Elizabeth Penney and Rebecca Fennessy for constructive comments on the manuscript. 


\section{References}

[1] E.M.P. Widmark, Principles and applications of medicolegal alcohol determination, Biomedical Publications, 1981.

[2] S. Bell, A beginner's guide to uncertainty of measurement, National Physical Laboratory Teddington, Middlesex, 2001.

[3] R. Gullberg, Measurement Uncertainty in Forensic Toxicology: Its Estimation, Reporting and Interpretation, Toxicity and Drug Testing, Prof. B. Acree). Available at: http://cdn. intechopen.

com/pdfs/28129/InTechmeasurement_uncertainty_in_forensic_toxicology_its_estima tion_reporting_and_interpretation.pdf [27 November 2013].

[4] N.R. Council, Strengthening forensic science in the United States: A path forward, (2009).

[5] G. Tully, Codes of Practice and Conduct for Forensic Science Providers and Practitioners in the Criminal Justice System (Issue 3), in: Forensic Science Regulator. , 2016.

[6] R.G. Gullberg, Estimating the uncertainty associated with Widmark's equation as commonly applied in forensic toxicology, Forensic Science International, 172 (2007) 33-39.

[7] J. Searle, Alcohol calculations and their uncertainty, Medicine, Science and the Law, 55 (2015) 58-64.

[8] D. Zuba, W. Piekoszewski, Uncertainty in theoretical calculations of alcohol concentration, in: Proc. 17th Internat. Conf. on Alcohol, Drugs and Traffic Safety, 2004.

[9] A. Norberg, A.W. Jones, R.G. Hahn, J.L. Gabrielsson, Role of variability in explaining ethanol pharmacokinetics: research and forensic applications, Clinical pharmacokinetics, 42 (2003) 1-31.

[10] W.M. Haynes, CRC handbook of chemistry and physics, CRC press, 2014.

[11] J.G. Speight, Lange's handbook of chemistry, McGraw-Hill New York, 2005.

[12] J.J. Cano-Gómez, G.A. Iglesias-Silva, E.O. Castrejón-González, M. Ramos-

Estrada, K.R. Hall, Density and Viscosity of Binary Liquid Mixtures of Ethanol + 1Hexanol and Ethanol + 1-Heptanol from (293.15 to 328.15) $\mathrm{K}$ at $0.1 \mathrm{MPa}$, Journal of Chemical and Engineering Data, 60 (2015) 1945-1955.

[13] B. González, A. Domínguez, J. Tojo, Dynamic viscosities, densities, and speed of sound and derived properties of the binary systems acetic acid with water, methanol, ethanol, ethyl acetate and methyl acetate at $T=(293.15,298.15$, and $303.15) \mathrm{K}$ at atmospheric pressure, Journal of Chemical and Engineering Data, 49 (2004) 1590-1596.

[14] E. Álvarez, Á. Cancela, R. Maceiras, J.M. Navaza, R. Táboas, Density, viscosity, excess molar volume, and viscosity deviation of three amyl alcohols + ethanol binary mixtures from 293.15 to $323.15 \mathrm{~K}$, Journal of Chemical and Engineering Data, 51 (2006) 940-945.

[15] I.S. Khattab, F. Bandarkar, M.A.A. Fakhree, A. Jouyban, Density, viscosity, and surface tension of water+ethanol mixtures from 293 to $323 \mathrm{~K}$, Korean Journal of Chemical Engineering, 29 (2012) 812-817.

[16] A. Kumagai, C. Yokoyama, Liquid Viscosity of Binary Mixtures of Methanol with Ethanol and 1-Propanol from 273.15 to $333.15 \mathrm{~K}$, International Journal of Thermophysics, 19 (1998) 3-13. 
1 [17] K. Kobayashi, Thermophysical Properties Handbook, (1990).

2 [18] J.A. Riddick, W.B. Bunger, T.K. Sakano, Organic Solvents, (1986).

3 [19] F.S. Agency, Food Labelling Regulations 1996, in, 1996.

4 [20] W.C. Kerr, D. Patterson, M.A. Koenen, T.K. Greenfield, Alcohol content variation

5 of bar and restaurant drinks in Northern California, Alcoholism: Clinical and

6 Experimental Research, 32 (2008) 1623-1629.

7 [21] B.K. Logan, G.A. Case, S. Distefano, Alcohol content of beer and malt

8 beverages: Forensic considerations, Journal of Forensic Sciences, 44 (1999) 1292-

91295.

10 [22] D.E. Briggs, P. Brookes, R. Stevens, C. Boulton, Brewing: science and practice, 11 Elsevier, 2004.

[23] E.B. Convention, Analytica-EBC, Carl, Getränke-Fachverl., 1998.

[24] G. Spedding, Chapter 7 - Alcohol and Its Measurement A2 - Bamforth, Charles W, in: Brewing Materials and Processes, Academic Press, San Diego, 2016, pp. 123-149.

[25] C. Papazian, complete joy of homebrewing, Quill, 2003.

[26] M. Hall, Brew By the Numbers-Add Up What's in Your Beer, in, Zymurgy.

[27] C.J.N. Balling, Die Bierbrauerei wissenschaftlich begründet und praktisch dargestellt, Tempsky, 1865.

[28] A.J. Cutaia, A.J. Reid, R. Alex Speers, Examination of the relationships between original, real and apparent extracts, and alcohol in pilot plant and commercially produced beers, Journal of the Institute of Brewing, 115 (2009) 318-327.

[29] G.G. Stewart, High-gravity brewing and distilling-past experiences and future prospects, Journal of the American Society of Brewing Chemists, 68 (2010) 1-9. [30] W.C. Kerr, T.K. Greenfield, J. Tujague, Estimates of the mean alcohol concentration of the spirits, wine, and beer sold in the United States and per capita consumption: 1950 to 2002, Alcoholism: Clinical and Experimental Research, 30 (2006) 1583-1591.

[31] W.C. Kerr, T.K. Greenfield, J. Tujague, S.E. Brown, The alcohol content of wine consumed in the US and per capita consumption: New estimates reveal different trends, Alcoholism: Clinical and Experimental Research, 30 (2006) 516-522.

[32] W.C. Kerr, Ethanol content of beer sold in the United States: Variation over time, across states and by individual drinks, in: Beer in Health and Disease Prevention, 2008, pp. 255-264.

[33] J.M. Alston, K.B. Fuller, J.T. Lapsley, G. Soleas, K.P. Tumber, Splendide mendax: False label claims about high and rising alcohol content of wine, Journal of Wine Economics, 6 (2011) 135-159.

[34] R. Economics, Top 10 UK Retailers by Sales in 2015, in.

[35] LWC Drinks List, in.

[36] I. Cabras, SIBA British Beer Survery Report, in, 2015.

[37] I. Cabras, SIBA British Beer Survery Report, in, 2016.

[38] CAMERA, Beer Styles, in, 2016.

[39] B.B.a.P. Association, Guidance notes on the dispense of draught beer by free flow and hand pull in, 1995.

[40] S. Adams, Nine in 10 pints 'are not pints', in: Daily Telegraph, 2009.

[41] W. Soroka, Fundamentals of Packaging Technology, Institute of Packaging

Professionals, 2009.

[42] Reducing fill losses, in, WRAP.

[43] Krones, krones Volumetic VOC and VODM-C can-filling systems, in. 
1 [44] L. Marais, DMAIC 6 Sigma of fill height optimisation of line 8 at SAB Alrode, in:

2 FACULTY OF ENGINEERING, BUILT ENVIRONMENT AND INFORMATION

3 TECHNOLOGY, UNIVERSITY OF PRETORIA, 2012.

4 [45] J. Northcote, M. Livingston, Accuracy of self-reported drinking: observational

5 verification of 'last occasion'drink estimates of young adults, Alcohol and Alcoholism, $646(2011) 709-713$.

7 [46] K. Poikolainen, Underestimation of recalled alcohol intake in relation to actual

8 consumption, British journal of addiction, 80 (1985) 215-216.

9 [47] M. Perrine, J.C. Mundt, J.S. Searles, D. Walter, I only had a couple of beers: International Conference on Alcohol, Drugs, and Traffic Safety, 1997, pp. 21-26. [48] M.S. Sommers, J.M. Dyehouse, S.R. Howe, J. Lemmink, T. Volz, M. Manharth, Validity of Self-Reported Alcohol Consumption in Nondependent Drinkers With Unintentional Injuries, Alcoholism: Clinical and experimental research, 24 (2000) 1406-1413.

[49] M.S. Sommers, J.M. Dyehouse, S.R. Howe, K. Wekselman, M. Fleming, "Nurse, I only had a couple of beers": validity of self-reported drinking before serious vehicular injury, American Journal of Critical Care, 11 (2002) 106-114. [50] R.L. Monk, D. Heim, A. Qureshi, A. Price, "I Have No Clue What I Drunk Last Night" Using Smartphone Technology to Compare In-Vivo and Retrospective SelfReports of Alcohol Consumption, PloS one, 10 (2015) e0126209.

[51] A.M. White, What happened? Alcohol, memory blackouts, and the brain, Alcohol Research and Health, 27 (2003) 186-196.

[52] N.R. Brown, Encoding, representing, and estimating event frequencies: A multiple strategy perspective, Frequency processing and cognition, (2002) 37-53. [53] A. Kalinowski, K. Humphreys, Governmental standard drink definitions and lowrisk alcohol consumption guidelines in 37 countries, Addiction, 111 (2016) 12931298.

[54] A. Kalinowski, K. Humphreys, Governmental standard drink definitions and lowrisk alcohol consumption guidelines in 37 countries, Addiction, 111 (2016) 12931298.

[55] B. Beer, Pub Association (BBPA)(2016) Statistical Handbook 2016, London, British Beer \& Pub Association.

[56] B.I. Group, Beverage Information Group Handbook (2016), 2016.

[57] C. Wilkinson, S. Allsop, T. Chikritzhs, Alcohol pouring practices among 65- to 74-year-olds in Western Australia, Drug and Alcohol Review, 30 (2011) 200-206. [58] W.C. Kerr, T.K. Greenfield, J. Tujague, S.E. Brown, A drink is a drink? Variation in the amount of alcohol contained in beer, wine and spirits drinks in a US methodological sample, Alcoholism: Clinical and Experimental Research, 29 (2005) 2015-2021.

[59] B. Wansink, K. Van Ittersum, Shape of glass and amount of alcohol poured: Comparative study of effect of practice and concentration, British Medical Journal, 331 (2005) 1512-1514.

[60] A.M. White, C.L. Kraus, J.D. Flom, L.A. Kestenbaum, J.R. Mitchell, K. Shah, H.S. Swartzwelder, College students lack knowledge of standard drink volumes: Implications for definitions of risky drinking based on survey data, Alcoholism: Clinical and Experimental Research, 29 (2005) 631-638.

[61] A.M. White, C.L. Kraus, L.A. McCracken, H.S. Swartzwelder, Do College Students Drink More Than They Think? Use of a Free-Pour Paradigm to Determine 
1 How College Students Define Standard Drinks, Alcoholism: Clinical and

2 Experimental Research, 27 (2003) 1750-1756.

3 [62] A. Stephens, A survey of hand-poured measures of spirit, Science and Justice, 436 191-194.

5 [63] J. Taylor, Introduction to error analysis, the study of uncertainties in physical 6 measurements, 1997.

$7 \quad[64] \mathrm{H}$. Ku, Notes on the use of propagation of error formulas, Journal of Research of 8 the National Bureau of Standards, 70 (1966).

9 [65] J.G. Amar, The Monte Carlo method in science and engineering, Computing in 10 Science and Engineering, 8 (2006) 9-19.

11 [66] P.L. Bonate, A brief introduction to Monte Carlo simulation, Clinical 12 pharmacokinetics, 40 (2001) 15-22.

13 [67] N. Metropolis, S. Ulam, The Monte Carlo Method, Journal of the American 14 Statistical Association, 44 (1949) 335-341. [68] R.L. Harrison, Introduction to Monte Carlo Simulation, AIP Conference Proceedings, 1204 (2010) 17-21.

[69] R.G. Gullberg, A.W. Jones, Guidelines for estimating the amount of alcohol consumed from a single measurement of blood alcohol concentration: re-evaluation of Widmark's equation, Forensic science international, 69 (1994) 119-130. [70] P. Wilson, Improving the methodology of drinking surveys, Statistician, 30 (1981) 159-167.

[71] J.S. Gill, M. Donaghy, Variation in the alcohol content of a 'drink' of wine and spirit poured by a sample of the Scottish population, Health Education Research, 19 (2004) 485-491.

[72] J.S. Gill, M. Donaghy, J. Guise, P. Warner, Descriptors and accounts of alcohol consumption: Methodological issues piloted with female undergraduate drinkers in Scotland, Health Education Research, 22 (2007) 27-36.

[73] S. Boniface, J. Kneale, N. Shelton, Actual and perceived units of alcohol in a self-defined "Usual Glass" of alcoholic drinks in England, Alcoholism: Clinical and Experimental Research, 37 (2013) 978-983.

[74] P.H. Lemmens, The alcohol content of self-report and 'standard' drinks, Addiction, 89 (1994) 593-601. 
1 Table 1: Allowable variations in alcohol content from labelled content in the EU and USA

\begin{tabular}{|c|c|c|c|c|}
\hline Country & Alcohol Type & Alcohol ABV & $\begin{array}{l}\text { Allowable } \\
\text { Variation }\end{array}$ & Reference \\
\hline \multirow{4}{*}{ EU } & Beer & $\begin{array}{c}\text { Not Exceeding } \\
5.5 \%\end{array}$ & $\pm 0.5 \%$ & \multirow{4}{*}{$\begin{array}{l}\text { EC Directive } \\
\text { (87/250/EEC) }\end{array}$} \\
\hline & Beer & $>5.5 \%$ & $\pm 1.0 \%$ & \\
\hline & $\begin{array}{l}\text { Beverages containing } \\
\text { macerated fruit or parts } \\
\text { of plants }\end{array}$ & - & $\pm 1.5 \%$ & \\
\hline & All others & - & $\pm 0.3 \%$ & \\
\hline \multirow{4}{*}{ USA } & Beer & - & $\pm 0.3 \%$ & 27 CFR 7.71 (c) \\
\hline & $\begin{array}{l}\text { Distilled Spirits (50 or } \\
100 \mathrm{ml} \text { bottles / } \\
\text { products containing } \\
\text { solids in excess of } 600 \\
\text { mg per } 100 \mathrm{ml} \text { ) }\end{array}$ & - & $\pm 0.25 \%$ & \multirow[t]{2}{*}{27 CFR 19.356 (c) } \\
\hline & All other distilled spirits & - & $\pm 0.15 \%$ & \\
\hline & Wine & $7-14 \%$ & $\pm 1.5 \%$ & 27 CFR 4.36 (b) \\
\hline
\end{tabular}


Table 2: Results of TTB Alcohol Beverage Sampling Program (ABSP) data from https://www.ttb.gov/sampling/ (accessed 21/04/2017)

\begin{tabular}{|c|c|c|c|c|c|c|c|c|c|c|c|c|}
\hline \multirow[b]{2}{*}{ Year } & \multirow[b]{2}{*}{ Beverage } & \multicolumn{5}{|c|}{ Raw Numbers } & \multicolumn{4}{|c|}{ Percentages } & \multicolumn{2}{|c|}{ Average } \\
\hline & & $\begin{array}{l}\text { Number } \\
\text { sampled }\end{array}$ & $\begin{array}{c}\text { Number } \\
\text { over } \\
\text { filled }\end{array}$ & $\begin{array}{c}\text { Number } \\
\text { under filled }\end{array}$ & $\begin{array}{c}\text { ABV: } \\
\text { Number } \\
\text { under }\end{array}$ & $\begin{array}{c}\text { ABV: } \\
\text { Number } \\
\text { over }\end{array}$ & Overfill & Underfill & ABV:under & ABV:over & ABV:under & ABV:over \\
\hline \multirow{3}{*}{2011} & Spirits & 337 & 0 & 5 & 9 & 60 & 0.0 & 1.5 & 2.7 & 17.8 & & \\
\hline & Beer & 204 & 6 & 8 & 13 & 8 & 2.9 & 3.9 & 6.4 & 3.9 & & \\
\hline & Wine & 117 & 0 & 0 & 1 & 2 & 0.0 & 0.0 & 0.9 & 1.7 & & \\
\hline \multirow{3}{*}{2012} & Spirits & 246 & 1 & 1 & 12 & 60 & 0.4 & 0.4 & 4.9 & 24.4 & & \\
\hline & Beer & 206 & 0 & 0 & 19 & 10 & 0.0 & 0.0 & 9.2 & 4.9 & & \\
\hline & Wine & 196 & 0 & 1 & 0 & 1 & 0.0 & 0.5 & 0.0 & 0.5 & & \\
\hline \multirow{3}{*}{2013} & Spirits & 275 & 0 & 2 & 15 & 50 & 0.0 & 0.7 & 5.5 & 18.2 & & \\
\hline & Beer & 239 & 0 & 0 & 23 & 30 & 0.0 & 0.0 & 9.6 & 12.6 & & \\
\hline & Wine & 154 & 0 & 0 & 3 & 1 & 0.0 & 0.0 & 1.9 & 0.6 & & \\
\hline \multirow{3}{*}{2014} & Spirits & 190 & 0 & 0 & 14 & 42 & 0.0 & 0.0 & 7.4 & 22.1 & $0.72 \%$ & $0.34 \%$ \\
\hline & Beer & 155 & 0 & 0 & 18 & 16 & 0.0 & 0.0 & 11.6 & 10.3 & & \\
\hline & Wine & 105 & 0 & 0 & 1 & 0 & 0.0 & 0.0 & 1.0 & 0.0 & & \\
\hline \multirow{3}{*}{2015} & Spirits & 154 & 0 & 0 & 8 & 40 & 0.0 & 0.0 & 5.2 & 26.0 & $0.95 \%$ & $0.58 \%$ \\
\hline & Beer & 158 & 0 & 0 & 10 & 28 & 0.0 & 0.0 & 6.3 & 17.7 & $0.86 \%$ & $0.69 \%$ \\
\hline & Wine & 138 & 0 & 0 & 1 & 1 & 0.0 & 0.0 & 0.7 & 0.7 & $2.70 \%$ & $2.00 \%$ \\
\hline \multirow{3}{*}{2016} & Spirits & 175 & 0 & 0 & 14 & 36 & 0.0 & 0.0 & 8.0 & 20.6 & $0.66 \%$ & $0.28 \%$ \\
\hline & Beer & 157 & 0 & 0 & 10 & 19 & 0.0 & 0.0 & 6.4 & 12.1 & $0.71 \%$ & $0.94 \%$ \\
\hline & Wine & 118 & 0 & 0 & 2 & 0 & 0.0 & 0.0 & 1.7 & 0 & $1.7 \%$ & - \\
\hline
\end{tabular}


Table 3: Average Alcoholic Beverage Concentrations (ABV) in the UK Based on Data from Tesco.com and LWC-drinks.co.uk

\begin{tabular}{|c|c|c|c|c|c|c|}
\hline Alcoholic Beverage & Mean ABV & Mode ABV & SD & $\begin{array}{c}\text { Range } \\
\text { (max) }\end{array}$ & $\begin{array}{c}\text { Range } \\
\text { (min) }\end{array}$ & $\mathbf{n}$ \\
\hline Alcopops & 4.0 & 4.0 & 0.0 & 4.0 & 4.0 & 10 \\
\hline Premix Spirits & 5.2 & 5.0 & 0.4 & 4.0 & 6.4 & 29 \\
\hline Alcoholic Sorbets & 4.7 & 4.7 & 0.0 & 4.7 & 4.7 & 9 \\
\hline Craft \& Specialist Beer & 5.7 & 5.6 & 1.1 & 4.1 & 9.2 & 35 \\
\hline Stout \& Porter & 4.0 & $\# \mathrm{~N} / \mathrm{A}$ & 1.3 & 2.0 & 6.0 & 8 \\
\hline Lager & 4.6 & 5.0 & 1.0 & 2.0 & 8.0 & 43 \\
\hline Draught Lager (AlI) & 4.5 & 5.0 & 0.5 & 3.6 & 5.0 & 25 \\
\hline Draught Lager (Standard) & 4.1 & 4.0 & 0.4 & 3.6 & 4.9 & 12 \\
\hline Draught Lager (Premium) & 4.8 & 5.0 & 0.3 & 4.1 & 5.0 & 13 \\
\hline Ale \& Bitter & 4.8 & 5.0 & 0.9 & 2.0 & 7.3 & 90 \\
\hline Cider (All) & 5.5 & 4.5 & 1.4 & 4.0 & 8.4 & 33 \\
\hline Cider (Bottled Fruit) & 4.1 & 4.0 & 0.2 & 4.0 & 5.0 & 29 \\
\hline Cider (craft) & 6.0 & 4.5 & 1.4 & 4.0 & 8.2 & 18 \\
\hline Cider (canned) & 5.0 & 4.5 & 1.2 & 3.5 & 8.4 & 13 \\
\hline Cider (Pear) & 4.5 & 4.5 & 0.0 & 4.5 & 4.5 & 3 \\
\hline Wine (White) & 12.0 & 12.5 & 1.4 & 5.5 & 14.0 & 166 \\
\hline Wine (Red) & 13.1 & 13.5 & 1.0 & 8.0 & 14.5 & 195 \\
\hline Wine (Rose) & 10.5 & 12.0 & 1.8 & 5.5 & 13.0 & 38 \\
\hline Champagne & 12.2 & 12.5 & 0.3 & 11.5 & 12.5 & 27 \\
\hline Prosecco & 11.1 & 11.0 & 0.3 & 10.5 & 11.5 & 10 \\
\hline Sherry & 17.1 & 17.5 & 1.4 & 15.0 & 19.0 & 28 \\
\hline Port & 19.8 & 20.0 & 0.4 & 19.0 & 20.0 & 18 \\
\hline Vodka (AII) & 39.0 & 40.0 & 1.3 & 37.5 & 40.0 & 24 \\
\hline Vodka (Normal) & 39.0 & 40.0 & 1.3 & 37.5 & 40.0 & 13 \\
\hline Vodka (Flavoured) & 38.9 & 40.0 & 1.3 & 37.5 & 40.0 & 11 \\
\hline Rum (AlI) & 38.5 & 40.0 & 6.6 & 21.0 & 63.0 & 25 \\
\hline Rum (White) & 43.1 & 37.5 & 11.2 & 37.5 & 63.0 & 5 \\
\hline Rum (Golden) & 39.6 & 40.0 & 0.9 & 37.5 & 40.0 & 7 \\
\hline Rum (Dark) & 39.0 & 40.0 & 1.4 & 37.5 & 40.0 & 5 \\
\hline Rum (Spiced) & 36.1 & 35.0 & 3.5 & 30.0 & 40.0 & 7 \\
\hline Gin (AII) & 38.2 & 37.5 & 4.6 & 26.0 & 43.1 & 22 \\
\hline Gin (standard) & 38.9 & 37.5 & 2.0 & 37.5 & 43.0 & 12 \\
\hline Gin (premium) & 41.2 & 40.0 & 1.4 & 40.0 & 43.1 & 7 \\
\hline Gin (Sloe) & 28.0 & 29.0 & 1.7 & 26.0 & 29.0 & 3 \\
\hline Brandy & 34.8 & 36.0 & 6.0 & 22.0 & 40.0 & 17 \\
\hline Cognac & 40.0 & 40.0 & 0.0 & 40.0 & 40.0 & 9 \\
\hline All Whisk(e)y & 40.2 & 40.0 & 3.7 & 20.0 & 50.0 & 83 \\
\hline Scotch Whisky & 40.7 & 40.0 & 2.5 & 28.0 & 46.0 & 59 \\
\hline Bourbon & 39.9 & 40.0 & 4.5 & 35.0 & 50.0 & 15 \\
\hline Irish Whiskey & 40.0 & 40.0 & 0.0 & 40.0 & 40.0 & 3 \\
\hline Other Whiskey & 36.0 & 43.0 & 8.6 & 20.0 & 43.0 & 6 \\
\hline
\end{tabular}


Table 4: Mean, Standard deviation and \%CV of the alcohol concentration (ABV) of various beer types found at the 2016 Great British Beer Festival (www.gbbf.org/beer)

\begin{tabular}{|lcccccccc|} 
& $\begin{array}{c}\text { Golden } \\
\text { Ale }\end{array}$ & Bitter & IPA & Mild & Porter & Stout & Speciality & Overall \\
\hline ABV (Mean) & 4.2 & 4.3 & 5.1 & 4.0 & 4.9 & 5.0 & 4.4 & 4.4 \\
\hline ABV (Mode) & 4.0 & 4.0 & 5.0 & 3.8 & 4.7 & 5.0 & 4.0 & 4.0 \\
\hline $\begin{array}{l}\text { Standard } \\
\text { Deviation }\end{array}$ & 0.4 & 0.5 & 1.0 & 0.6 & 0.7 & 1.0 & 0.4 & 0.7 \\
\hline \%CV & 8.5 & 11.9 & 20.1 & 15.5 & 14.8 & 19.4 & 8.6 & 15.8 \\
\hline $\begin{array}{l}\text { ABV Range } \\
\text { (min) }\end{array}$ & 3.6 & 3.5 & 3.5 & 3.0 & 4.0 & 3.7 & 3.8 & 3.0 \\
\hline $\begin{array}{l}\text { ABV Range } \\
\text { (max) }\end{array}$ & 5.5 & 6.6 & 7.5 & 6.0 & 6.5 & 7.5 & 5.2 & 7.5 \\
\hline $\mathrm{n}=$ & 140 & 108 & 43 & 36 & 12 & 24 & 23 & 386 \\
\hline
\end{tabular}


Table 5: Allowable variations in beverage volume in the EU and USA

\begin{tabular}{|c|c|c|c|c|}
\hline Country & Alcohol Type & Draft/bottle & $\begin{array}{l}\text { Allowable } \\
\text { Variation }\end{array}$ & Reference \\
\hline EU & All (Serving) Line & Draft $<200 \mathrm{ml}$ & $\pm 5 \%$ & \\
\hline EU & All (Serving) Brim & Draft $<200 \mathrm{ml}$ & $\begin{array}{c}0-10 \% \\
\pm 5 \%\end{array}$ & \\
\hline EU & All (Serving) Line & Draft $>200 \mathrm{ml}$ & $+2.5 \%$ & \\
\hline EU & All (Serving) Brim & Draft $>200 \mathrm{ml}$ & $\begin{array}{c}0-10 \mathrm{ml} \\
+5 \%\end{array}$ & $\begin{array}{l}\text { Annex MI- } \\
008\end{array}$ \\
\hline EU & All (transfer) - Line & Draft $<100 \mathrm{ml}$ & $\pm 2 \mathrm{ml}$ & \\
\hline EU & All (transfer) - Brim & Draft $<100 \mathrm{ml}$ & $0-4 \mathrm{ml}$ & \\
\hline EU & All (transfer) - Line & Draft $>100 \mathrm{ml}$ & $\pm 3 \%$ & \\
\hline EU & All (transfer) - Brim & Draft $>100 \mathrm{ml}$ & $0-6 \%$ & \\
\hline US & \multirow{4}{*}{ Pre-packaged } & Bottle (<100ml) & $\pm 4.5 \%$ & \multirow{4}{*}{$\begin{array}{l}27 \text { CFR } \\
19.356\end{array}$} \\
\hline US & & Bottle (101 - 375ml) & $\pm 3.0 \%$ & \\
\hline US & & Bottle (376-999 ml) & $\pm 2.0 \%$ & \\
\hline US & & Bottle (>1000ml) & $\pm 1.5 \%$ & \\
\hline Country & Alcohol Type & Draft/bottle & $\begin{array}{c}\text { Tolerable } \\
\text { negative } \\
\text { error (TNE) }\end{array}$ & Reference \\
\hline EU & \multirow{6}{*}{ Pre-packaged } & Bottle ( $5-50 \mathrm{ml})$ & $9 \%$ & \multirow{6}{*}{$\begin{array}{l}\text { Annex MI- } \\
008\end{array}$} \\
\hline EU & & Bottle (50- $100 \mathrm{ml})$ & $4.5 \mathrm{ml}$ & \\
\hline EU & & Bottle (100 - $200 \mathrm{ml})$ & $4.50 \%$ & \\
\hline EU & & Bottle $(200-300 \mathrm{ml})$ & $9 \mathrm{ml}$ & \\
\hline EU & & Bottle (300 - $500 \mathrm{ml})$ & $3 \%$ & \\
\hline EU & & $\begin{array}{c}\text { Bottle (500-1000 } \\
\mathrm{ml})\end{array}$ & $15 \mathrm{ml}$ & \\
\hline
\end{tabular}


Table 6: Experimental determination of self-pour measures of alcoholic beverages. A) and B) in UK units. C) Volume (ml)

A)

\begin{tabular}{|l|cccc|ccc|}
\hline \multicolumn{1}{|c|}{ Study } & \multicolumn{3}{|c|}{ Spirits } & \multicolumn{3}{c|}{ Wine } \\
& Mean (units) & SD & $\mathbf{9 5 \%} \mathbf{~ C l}$ & $\mathbf{n}$ & Mean (units) & SD & $\mathbf{9 5 \% ~ C l}$ \\
\hline Wilson [70] & 1.44 & 0.72 & & $?$ & & \\
Gill \& Donaghy [71] & 2.13 & & $2.16-2.41$ & 238 & 1.92 & $1.86-1.97$ & 238 \\
Gill et al [72] & 2.24 & & $1.8-2.7$ & 19 & 1.98 & $1.7-2.2$ & 19 \\
Boniface et al [73] & 1.93 & 0.78 & & 201 & 1.90 & 0.8 & 264 \\
\hline
\end{tabular}

B)

\begin{tabular}{|c|c|c|c|c|c|c|c|c|c|c|c|c|}
\hline \multirow{2}{*}{ Study } & \multicolumn{4}{|c|}{ Spirits } & \multicolumn{4}{|c|}{ Wine } & \multicolumn{4}{|c|}{ Beer } \\
\hline & Female & & $M a$ & & Female & & 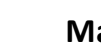 & & Fem & & & \\
\hline & Mean (units) & SD & Mean & SD & Mean (units) & SD & Mean & SD & $\begin{array}{l}\text { Mean } \\
\text { (units) }\end{array}$ & SD & Mean & SD \\
\hline Wilkinson et al. [57] & 1.56 & 3.51 & 1.98 & 3.40 & 1.48 & 0.22 & 1.73 & 0.94 & 0.99 & 1.75 & 1.44 & 1.13 \\
\hline Kerr et al. [58] & 2.48 & 1.81 & 2.66 & 1.55 & 2.01 & 1.33 & 1.87 & 1.00 & 1.75 & 1.16 & 1.60 & 0.36 \\
\hline
\end{tabular}

C)

\begin{tabular}{|c|c|c|c|c|c|c|c|c|}
\hline \multirow{3}{*}{ Study } & \multicolumn{4}{|c|}{ Spirits } & \multicolumn{4}{|c|}{ Wine } \\
\hline & \multicolumn{2}{|l|}{ Female } & \multicolumn{2}{|l|}{ Male } & \multicolumn{2}{|c|}{ Female } & \multicolumn{2}{|l|}{ Male } \\
\hline & Volume (ml) & SD & Volume (ml) & SD & Volume (ml) & SD & Volume (ml) & SD \\
\hline Wilson [70] & 36 & 18 & $\begin{array}{l}\text { Only mean } \\
\text { given }\end{array}$ & & & & & \\
\hline Lemmens [74] & 48 & 30 & 44 & 16 & 106.00 & 33 & 112 & 33 \\
\hline Gill \&Donaghy [71] & 57.1 & 24 & $\begin{array}{l}\text { Only mean } \\
\text { given }\end{array}$ & & & & & \\
\hline
\end{tabular}

Where the data was not shown as SD (SE) it was converted to SD. 
Table 7A: The revised uncertainties volume, $A B V$ and amount of alcohol from Gulberg and Zuba based on the uncertainties found in this paper (GEP method).

\begin{tabular}{|c|c|c|c|c|c|c|c|c|}
\hline Publication & $\begin{array}{c}\text { Volume } \\
(\mathbf{m l})\end{array}$ & $\begin{array}{c}\text { Volume } \\
\text { \%CV }\end{array}$ & $\begin{array}{c}\text { Density } \\
\left(\mathbf{g} / \mathbf{c m}^{\mathbf{3}}\right)\end{array}$ & $\begin{array}{c}\text { Density } \\
\mathbf{\%} \mathbf{C V}\end{array}$ & $\begin{array}{c}\text { ABV } \\
(\mathbf{\%} / \mathbf{v})\end{array}$ & $\begin{array}{c}\text { ABV } \\
\text { \%CV }\end{array}$ & $\begin{array}{c}\text { Calculated } \\
\text { Alcohol } \\
\text { Amount } \\
\mathbf{( g )}\end{array}$ & $\begin{array}{c}\text { Calculated } \\
\text { Alcohol } \\
\text { Amount } \\
\text { \%CV }\end{array}$ \\
\hline Gullberg [6] & 354.88 & 1 & 0.78974 & 0.07 & 4 & 2.5 & 11.21 & 2.69 \\
\hline Zuba [8] & 250 & 1.67 & 0.78974 & 0.07 & 40 & 0.8 & 78.97 & 1.85 \\
\hline
\end{tabular}

Table 7B: The revised uncertainties volume, $A B V$ and amount of alcohol from Gulberg and Zuba based on the uncertainties found in this paper (Monte Carlo Method).

\begin{tabular}{|c|c|c|c|c|c|c|c|c|}
\hline Publication & $\begin{array}{c}\text { Volume } \\
(\mathbf{m l})\end{array}$ & $\begin{array}{c}\text { Volume } \\
\text { \%CV }\end{array}$ & $\begin{array}{c}\text { Density } \\
\left(\mathbf{g} / \mathbf{c m}^{3}\right)\end{array}$ & $\begin{array}{c}\text { Density } \\
\% \mathbf{C V}\end{array}$ & $\begin{array}{c}\text { ABV } \\
(\mathbf{\% v} / \mathbf{v})\end{array}$ & $\begin{array}{c}\text { ABV } \\
\% \mathbf{C V}\end{array}$ & $\begin{array}{c}\text { Calculated } \\
\text { Alcohol } \\
\text { Amount } \\
\mathbf{( g )}\end{array}$ & $\begin{array}{c}\text { Calculated } \\
\text { Alcohol } \\
\text { Amount } \\
\% \mathbf{C V}\end{array}$ \\
\hline Gullberg [6] & 354.88 & 1 & 0.78974 & 0.07 & 4 & 2.5 & 11.2 & 1.69 \\
\hline Zuba [8] & 250 & 1.67 & 0.78974 & 0.07 & 40 & 0.8 & 79.0 & 1.26 \\
\hline
\end{tabular}


Table 8: The proportion that each variable in the Widmark equation contributes to estimating A) the blood alcohol concentration $(\mathrm{Ct})$ or $\mathrm{B}$ ) the volume of drink $(\mathrm{v})$ consumed based on data from Gullberg and this Study

A)

\begin{tabular}{|c|c|c|c|c|c|c|}
\hline \multicolumn{4}{|c|}{ Gullberg Data } & \multicolumn{3}{|c|}{ Data from this study } \\
\hline Variable & Value & SD & $\begin{array}{c}\text { Percentage of } \\
\text { Total } \\
\text { Uncertainty }\end{array}$ & Variable & SD & $\begin{array}{c}\text { Percentage } \\
\text { of Total } \\
\text { Uncertainty }\end{array}$ \\
\hline v & $3550 \mathrm{ml}$ & $103 \mathrm{ml}$ & $14.10 \%$ & $3550.0 \mathrm{ml}$ & $48.4 \mathrm{ml}$ & $3.60 \%$ \\
\hline $\mathrm{z}$ & $0.040000 \% \mathrm{v} / \mathrm{v}$ & $693 \times 10^{-6} \% \mathrm{v} / \mathrm{v}$ & $5.00 \%$ & $0.040000 \% \mathrm{v} / \mathrm{v}$ & $577 \times 10^{-6} \% \mathrm{v} / \mathrm{v}$ & $4.00 \%$ \\
\hline$d$ & $0.78900 \mathrm{~g} / \mathrm{ml}$ & $4.56 \times 10^{-3} \mathrm{~g} / \mathrm{ml}$ & $0.60 \%$ & $0.78974 \mathrm{~g} / \mathrm{ml}$ & $3.41 \times 10^{-3} \mathrm{~g} / \mathrm{ml}$ & $0.40 \%$ \\
\hline W & $81.640 \mathrm{Kg}$ & $0.943 \mathrm{Kg}$ & $2.20 \%$ & $81.640 \mathrm{Kg}$ & $0.943 \mathrm{Kg}$ & $2.60 \%$ \\
\hline$\beta$ & $14.80 \mathrm{mg} / 100 \mathrm{ml} / \mathrm{h}$ & $1.88 \mathrm{mg} / 100 \mathrm{ml} / \mathrm{h}$ & $36.00 \%$ & $14.80 \mathrm{mg} / 100 \mathrm{ml} / \mathrm{h}$ & $1.88 \mathrm{mg} / 100 \mathrm{ml} / \mathrm{h}$ & $41.20 \%$ \\
\hline \multirow[t]{2}{*}{$\mathrm{t}$} & $5.0000 \mathrm{~h}$ & $0.0577 \mathrm{~h}$ & $0.30 \%$ & $5.0 \mathrm{~h}$ & $0.0577 \mathrm{~h}$ & $0.40 \%$ \\
\hline & & Total $(v, z, d)$ & $19.70 \%$ & & Total $(v, z, d)$ & $8.00 \%$ \\
\hline
\end{tabular}

B)

\section{Gullberg Data}

\begin{tabular}{cllr}
\multicolumn{3}{c}{ Gullberg Data } \\
\hline Variable & \multicolumn{1}{c}{ Value } & \multicolumn{1}{c}{ SD } & $\begin{array}{c}\text { Percentage of } \\
\text { Total } \\
\text { Uncertainty }\end{array}$ \\
\hline Cmax & $114.00 \mathrm{mg} / 100 \mathrm{ml}$ & $1.91 \mathrm{mg} / 100 \mathrm{ml}$ & $2.00 \%$ \\
$\beta$ & $14.80 \mathrm{mg} / 100 \mathrm{ml} / \mathrm{h}$ & $1.88 \mathrm{mg} / 100 \mathrm{ml} / \mathrm{h}$ & $41.20 \%$ \\
$\mathrm{t}$ & $5.0000 \mathrm{~h}$ & $0.0577 \mathrm{~h}$ & $0.40 \%$ \\
$\mathrm{r}$ & $0.7300 \mathrm{~L} / \mathrm{Kg}$ & $0.0388 \mathrm{~L} / \mathrm{Kg}$ & $47.40 \%$ \\
$\mathrm{~W}$ & $81.640 \mathrm{Kg}$ & $0.943 \mathrm{Kg}$ & $2.60 \%$ \\
$\mathrm{~d}$ & $0.78900 \mathrm{~g} / \mathrm{ml}$ & $4.56 \times 10^{-3} \mathrm{~g} / \mathrm{ml}$ & $0.60 \%$ \\
$\mathrm{z}$ & $0.040000 \% \mathrm{v} / \mathrm{v}$ & $693 \times 10^{-6} \% \mathrm{v} / \mathrm{v}$ & $5.80 \%$ \\
\hline & & Total (z,d) & $6.40 \%$
\end{tabular}

Data from this study

Percentage

of Total

\begin{tabular}{llr}
\multicolumn{1}{c}{ Variable } & \multicolumn{1}{c}{ SD } & Uncertainty \\
\hline $114.00 \mathrm{mg} / 100 \mathrm{ml}$ & $1.91 \mathrm{mg} / 100 \mathrm{ml}$ & $2.00 \%$ \\
$14.80 \mathrm{mg} / 100 \mathrm{ml} / \mathrm{h}$ & $1.88 \mathrm{mg} / 100 \mathrm{ml} / \mathrm{h}$ & $42.10 \%$ \\
$5.0000 \mathrm{~h}$ & $0.0577 \mathrm{~h}$ & $0.40 \%$ \\
$0.7300 \mathrm{~L} / \mathrm{Kg}$ & $0.0388 \mathrm{~L} / \mathrm{Kg}$ & $48.40 \%$ \\
$81.640 \mathrm{Kg}$ & $0.943 \mathrm{Kg}$ & $2.60 \%$ \\
$0.78974 \mathrm{~g} / \mathrm{ml}$ & $3.41 \times 10^{-3} \mathrm{~g} / \mathrm{ml}$ & $0.40 \%$ \\
$0.040000 \% \mathrm{v} / \mathrm{v}$ & $577 \times 10^{-6} \% \mathrm{v} / \mathrm{v}$ & $4.10 \%$ \\
\hline & Total $(\mathbf{z}, \mathrm{d})$ & $4.50 \%$ \\
\hline
\end{tabular}

